\title{
Bony Sclerosis and the Battered Child
}

\author{
A.A. DeSmet, M.D. ${ }^{1}$, L.R. Kuhns, M.D., R.A. Kaufman, M.D., and J.F. Holt, M.D. \\ Division of Pediatric Radiology, C.S. Mott Children's Hospital, University of Michigan Medical Center, Ann Arbor, Michigan, USA
}

\begin{abstract}
A case of child battering in a four monthold infant is presented. In additional to typical physical and radiographic findings isolated sclerosis of the left tibia is described. Diffuse bony sclerosis in battered children has been proposed as evidence for an underlying metaphyseal fragility. Similar sclerosis in an isolated bone in our case suggests that the diffuse bony sclerosis seen in some of these battered children may reflect a more widespread posttraumatic change and not a basic metabolic defect. A radionuclide bone scan was also normal in this patient.
\end{abstract}

Key words: Child abuse, skeletal changes - Trauma, bone scanning - Skeleton, traumatic changes.

Radiographic evaluation for occult skeletal fractures plays an essential role in the diagnosis of the battered child syndrome. Since the pioneering work by Caffey [2], many reports have documented its osseous manifestations $[1,3,4,10,11,12]$. However, the association of bony sclerosis with child battering has only occasionally been described $[3,7,11]$. This finding has special significance because of the controversy as to underlying metaphyseal fragility in some of these traumatized children [7]. We recently encountered a case which offers further insight into this matter.

\section{Case History}

A four-month-old white male infant was admitted to C.S. Mott Children's Hospital after a generalized seizure. Two similar seizures

\footnotetext{
$1 \quad$ Present address: Boone Clinic, Little Creek Naval Amphibious Base, Norfolk, Virginia, USA

Address reprint requests to: L.R. Kuhns, M.D., Division of Pediatric Radiology, C.S. Mott Children's Hospital, University of Michigan Medical Center, Ann Arbor, MI 48109, USA
}

had occurred one month previously. The infant was the product of an uncomplicated pregnancy and vaginal delivery. Maternal anemia had been noted on the two prenatal visits. Although full term, the infant's birth weight was $2.6 \mathrm{~kg}$.

Maternal history revealed that the infant was the second child of a 16-year-old unwed mother. His mother had left sehool after two years in the eighth grade when she became pregnant with his 16-month-old sister. Her parents were divorced and she lived alone in an apartment without a telephone or transportation. She was dependent upon occasional visits from her mother and friends for shopping and laundry.

Initial evaluation revealed a lethargic, dehydrated infant with a tense, pulsatile anterior fontanelle. His weight was $5.2 \mathrm{~kg}$ (less than the third percentile) and his length was $59 \mathrm{~cm}$ (second percentile). His head circumference was $41 \mathrm{~cm}$ (35th percentile). Physical examination was normal except for bilateral subretinal macular hemorrhages and a splinter hemorrhage in the left eye. There were no dermal lesions except for a mild diaper rash.

The following blood tests were normal: fasting blood sugar, blood urea nitrogen, creatinine, electrolytes, calcium, phosphorous, erythrocyte sedimentation rate, prothrombin time, partial thromboplastin time, thrombin clotting time, and fibrinogen. He was initially anemic with a hemoglobin of $9.9 \mathrm{gm} / 100 \mathrm{ml}$ but had a hemoglobin of $12.9 \mathrm{gm} / 100 \mathrm{ml}$ with a reticulocyte count of $4.9 \%$ three weeks later. An initial unexplained thrombocytosis of 775,000 platelets $/ \mathrm{mm}^{3}$ resolved by the time of discharge.

The cell count, glucose, and protein in his cerebrospinal fluid were normal. His urine amino acid screen, urine for porphyrins, and serum antibody screens for cytomegalovirus, rubella, herpes, and toxoplasmosis were all negative. The electroencephalogram showed a mild diffuse neuronal disturbance and computerized tomography of the brain suggested early cortical degeneration.

Radiographic examination of the skull and chest were normal. His bone age of three months was consistent with his chronological age. A healing fracture of the left ulna was noted (Fig. 1), and diffuse sclerosis with intermixed lucencies of the diaphysis of the left tibia was noted which resembled radiographic changes of fibrous dysplasia (Fig. 2). A ${ }^{99^{m}}$ Tc-pyrophosphate bone scan performed with a pinhole collimator for magnification was interpreted as normal (Fig. 3).

The patient's mother initially denied any previous episodes of trauma. When confronted with the evidence for child abuse, she admitted tossing the child in the air several times prior to the first seizure. She also recounted several episodes of trauma allegedly caused by the 16-month-old sibling. She agreed to voluntary placement of the child with a foster mother. Evaluation of the sibling revealed no evidence of abuse. 

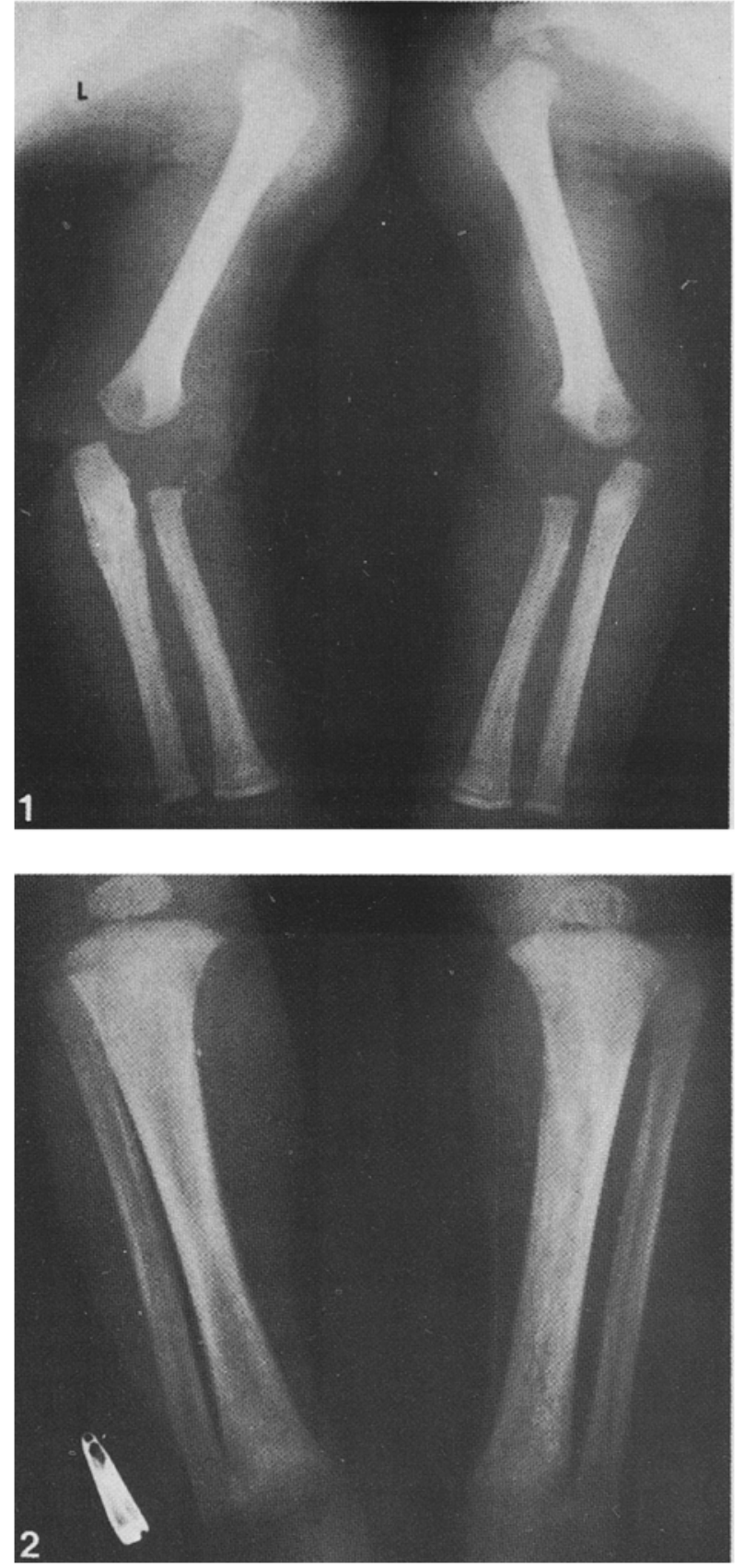

Fig. 1. Anterior and posterior radiographs of the arms. Diffuse periosteal reaction is present along the shafts of all the long bones which may be seen normally at this age. The proximal left ulna is widened from a previous fracture

Fig. 2. Anterior and posterior radiographs of the lower legs. Diffuse periosteal reaction is present along the shafts of both tibiae and fibulac. The diaphysis of the left tibia is sclerotic with mixed areas of lucencies

Fig. 3A and B. Posterior views of the upper half (A) and lower half (B) of ${ }^{99 m} \mathrm{Tc}$-pyrophosphate whole body scan (pinhole imagining). This isotope study was interpreted as negative
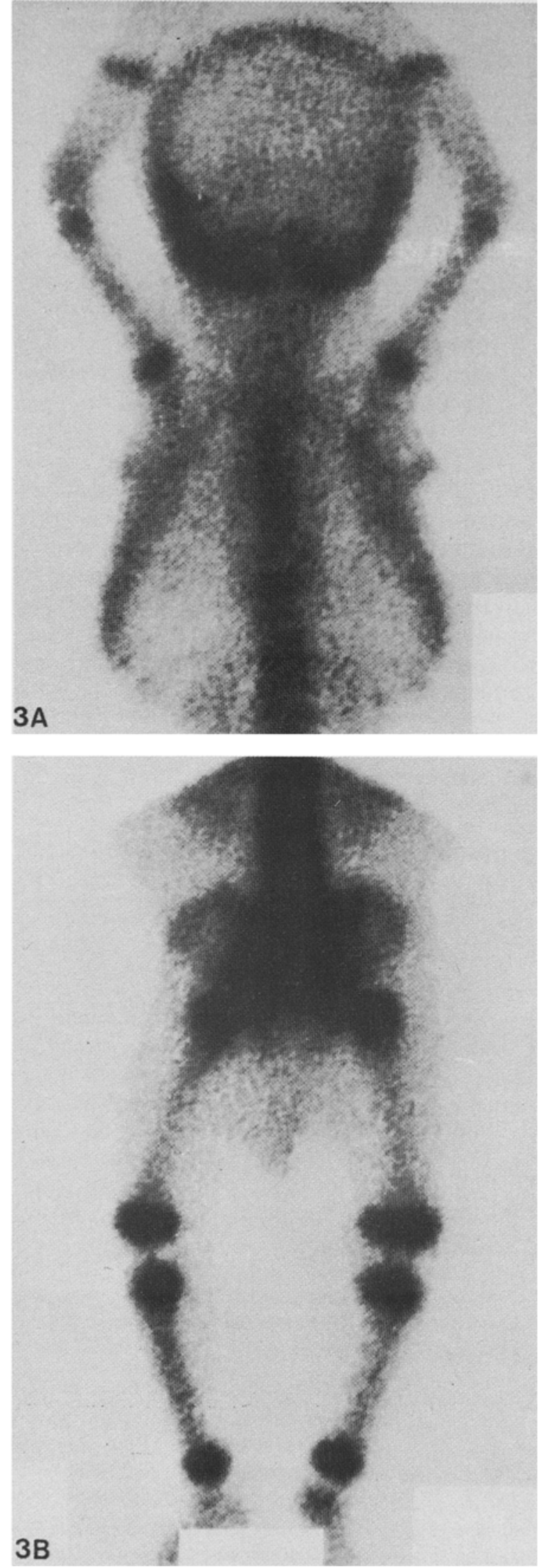
The patient gained $1.1 \mathrm{~kg}$ during the three weeks of hospitalization and became an active, happy infant. Follow-up evaluation at seven and nine months showed normal physical and mental development with partial resolution of the macular hemorrhages. His height and weight stabilized at the 50th-60th percentile after initial rapid increases.

\section{Discussion}

The traumatic skeletal lesions associated with the battered child syndrome are most comprehensively described by Caffey [3]. These lesions include fractures and dislocations, metaphyseal infractions, extensive involucrum formation, metaphyseal cupping, bowing of the diaphyses, and ectopic accessory epiphyseal ossification centers. The fractures are characteristically multiple and in various stages of healing. The diagnostic importance of 'unusual' fractures of the distal clavicles, ribs, scapulae, sternum, and spine is emphasized by Kogutt [8]. Intramedullary fat necrosis caused by traumatic pancreatitis has also been reported recently [13].

The most important feature of this case is the mixed sclerosis and lucencies of the left tibia. This "chalkiness" in association with the battered child syndrome has been described previously by only three authors $[3,7,11]$. Caffey illustrates a case of phalangeal sclerosis caused by repeated trauma in a patient with congenital insensitivity to pain but draws no conclusion from his observation [3]. Hiller feels that the diffuse sclerosis seen in his cases suggests an underlying metaphyseal fragility [7]. He postulates that multiple metaphyseal fractures may not be diagnostic of a battered child. This conclusion is based on a "dense' texture of the entire skeleton in five patients who had epiphyseal plate fractures on both sides of multiple joints. Bone biopsies revealed immature woven bone suggesting a collagen abnormality. It is unclear in his report whether only radiographic abnormalities were present in these children, or whether physical stigmata of abuse were also present. The etiology of these changes is still unproven but we agree with Silverman that it most likely "reflects productive changes in bone owing to multiple repetitive trauma insufficient to cause obvious fractures or the usual reparative changes ...' [11].

If Hiller is correct that the classically described pattern of multiple metaphyseal fractures may also be due to unusual bony fragility, an erroneous diagnosis of child abuse might be made. This case demonstrates that the bony sclerosis which he describes may occur as a localized process undoubtedly as the result of trauma. An underlying collagen defect should give diffuse changes. It does not conclusively disprove the existence of an underlying metaphyseal fragility in some supposedly battered children. Review of other cases of child abuse from our files did not reveal such pronounced sclerosis with lucencies in other cases in our limited material. This report may stimulate further work by others with greater experience with child battering to resolve this uncertainty.

An interesting sidelight in this case is the negative radionuclide bone scan despite obvious periosteal reaction on the radiographs. The increasing usage of bone scanning for the evaluation of trauma [5, 6,9 ] would suggest a highly sensitive method of diagnosis for this syndrome. In fact Fordham states that 'the battered child will demonstrate far more abnormality on the bone scan than can be demonstrated roentgenographically ...' [6]. In this case the isotope study may have been negative due to lack of resolution because of the patient's small size or due to the stage of development of the osseous changes at the time of the scan.

\section{References}

1. Akbarnia, B., Torg, J.S., Kirkpatrick, J., Sussman, S.: Manifestations of the battered child syndrome. J. Bone Joint Surg. 56A, 1159 (1974)

2. Caffey, J.: Multiple fractures in the long bones of infants suffering from chronic subdural hematoma. Am. J. Roentgenol. Radium Ther. Nucl. Med. 56, 163 (1946)

3. Caffey, J.: Some traumatic lesions in growing bones other than fractures and dislocations: clinical and radiological features. Br. J. Radiol. 30, 225 (1957)

4. Caffey, J.: The parent-infant traumatic stress syndrome. Am. J. Roentgenol. Radium Ther. Nucl. Med. 114, 218 (1972)

5. Ell, P.J., Dash, J., Raymond, J.: Bone scanning: A review on purpose and method. Skeletal Radiol. 1, 33 (1976)

6. Fordham, E.W., Ramachandran, P.C.: Radionuclide scanning of osseous trauma. Semin. Nucl. Med. 4, 411 (1974)

7. Hiller, H.G.: Battered or not - a reappraisal of metaphyseal fragility. Am. J. Roentgenol. Radium Ther. Nucl. Med. 114, 241 (1972)

8. Kogutt, M.S., Swischuk, L.E., Fagan, O.J.: Patterns of injury and significance of uncommon fractures in the battered child syndrome. Am. J. Roentgenol. Radium Ther. Nucl. Med. 121, 143 (1974)

9. Marty, R., Denney, J.D., McKamey, M.R., Rowley, M.J.: Bone trauma and related benign disease: Assessment by bone scanning. Semin. Nucl. Med. 6, 107 (1976)

10. Silverman, F. N.: The roentgen manifestations of unrecognized skeletal trauma in infants. Am. J. Roentgenol. Radium Ther. Nucl. Med. 69, 413 (1953)

11. Silverman, F.N.: The battered child. R.E. Helfer and C.H. Kempe, eds., University of Chicago Press 1968

12. Silverman, F.N.: Unrecognized trauma in infants, the battered child syndrome, and syndrome of Ambrose Tardieu. Radiology 104, 337 (1972)

13. Slovis, T.L., Berdon, W.E., Haller, J.O., Baker, D.H., Rosen, L. : Pancreatitis and the battered child syndrome. Am. J. Roentgenol. Radium Ther. Nucl. Med. 125, 456 (1975) 